\title{
Crack Length Evaluation for Cyclic and Sustained Loading at High Temperature Using Potential Drop
}

Erik Storgärds and Kjell Simonsson

\author{
Linköping University Post Print
}

Tweet

N.B.: When citing this work, cite the original article.

Original Publication:

Erik Storgärds and Kjell Simonsson, Crack Length Evaluation for Cyclic and Sustained Loading at High Temperature Using Potential Drop, 2015, Experimental mechanics, (55), 3, 559-568.

http://dx.doi.org/10.1007/s11340-014-9963-2

Copyright: Society for Experimental Mechanics (SEM)

http://sem.org/

Postprint available at: Linköping University Electronic Press

http://urn.kb.se/resolve?urn=urn:nbn:se:liu:diva-117241 


\title{
Crack length evaluation for cyclic and sustained loading at high temperature using potential drop
}

\author{
Erik Storgärds*, Kjell Simonsson \\ Division of Solid Mechanics, Linköping University, SE-58183 Linköping, Sweden
}

\begin{abstract}
Crack length evaluations for cyclic loading and sustained loading at high temperature and a mix of both have been conducted on Inconel 718 surface crack specimens at $550^{\circ} \mathrm{C}$. The choice of method for evaluating the crack length is seen to have a nonnegligible impact on the resulting crack propagation rate values. In this paper, some aspects regarding how to evaluate such testing when using the potential drop technique are presented, with the aim of giving a firm explanation on how to proceed for the best possible result.
\end{abstract}

Keywords: Fatigue crack propagation, Fatigue test evaluation, Sustained load, Dwell time effects, Crack length evaluation, Potential drop

\section{Introduction}

Long dwell times at high temperature are frequently seen in e.g. gas turbine applications, e.g. at constant power output for land based turbines, at cruise for aero engines or at slowly applied ramps of engine thrust. The effect of hold times and the associated change in crack growth behaviour has been studied in e.g. [1-4], where it is shown that an increased crack growth rate is gained which also causes intergranular crack growth, this in contrast to cyclic loadings of not too low frequency in which mainly transgranular crack growth is observed. Further, in e.g. [4, 5] a characterisation of how loading frequencies influence the hold time behaviour of Inconel 718 was made, and it was shown that not only sustained load but also e.g. a triangular wave of low loading frequency gave hold time effects, which further emphasises the importance of being able to predict the phenomenon.

Several authors have studied the effect of dwell times (sustained load/hold times) on various materials, e.g. Inconel 718 [6-10], low-alloy steel [11], Inconel 100 [2], and Inconel 718, 706, 783, Udimet 720 and Waspaloy [12]; all for various temperatures (although mainly for $650^{\circ} \mathrm{C}$ ) and lengths of dwell time. The main conclusion drawn in all of these works is that a volume of material around the crack tip is affected by some damage mechanism. The two dominating explanation models for the

\footnotetext{
* Corresponding author. Tel.: + 46 (0)13282475.

E-mail address: erik.storgards@liu.se (E. Storgärds).
} 
phenomenon are dynamic embrittlement (DE) and stress accelerated grain boundary oxidation (SAGBO), which describe different ways in which oxygen (among other embrittling elements) affects the grain boundaries [13,14]. Briefly, the two mechanisms can be described as follows; DE is a cracking process where embrittling elements (e.g. oxygen) weaken the grain boundaries, which allows for further crack advancement as they crack, see e.g. $[8,11,13]$. SAGBO on the other hand involves oxidation of grain boundaries and their subsequent cracking [14]. The active mechanism will leave stronger grain boundaries behind in the form of unbroken ligaments and islands of unbroken material, which can be seen when breaking up specimens and investigating the fracture surfaces $[11,15]$.

It is at this stage important to note that there exist two distinct options of how to define the zone of material damage: (1) the local region where the oxidation processes take place in the undamaged material (nanometre scale [16]), and (2) part of the area behind the boundary of undamaged material, consisting of unbroken ligaments and islands of unbroken material (which may be tenths of $\mathrm{mm}$ in depth [17]). The latter viewpoint (adopted in this paper) implies a macroscopic crack front located somewhere in between the boundary of undamaged material and the completely through-cracked area with no left overs from the damage process, which is what the potential drop (PD) signal defines as the size of the crack [18]. Alternative measurement techniques, e.g. by compliance, have confirmed the same observations, namely that crack lengths are underestimated compared to measurements on the fracture surfaces [2]. From the discussion above, it becomes apparent that one not only has to consider the damaged zone when evaluating post-mortem fracture surfaces, but also when constructing crack propagation models, where the load history and its effect on the material crack propagation resistance must be taken into account. In Fig. 1 a schematic illustration of how the damaged zone $D$ and crack length are related to each other can be found. Although comprehensive studies of sustained load at high temperatures and the observed effects have been carried out, see above, the evaluation method and its consequences on the crack growth rate description has not frequently been studied.

An investigation of how to predict the correct crack propagation rate by using different evaluation methods will therefore be most important in order to design for safe life of relevant components. In this paper, three different crack length evaluation methods are investigated on Inconel 718 surface crack specimens that have been subjected to cyclic load, sustained load, and a mix of both, see [17], for the temperature

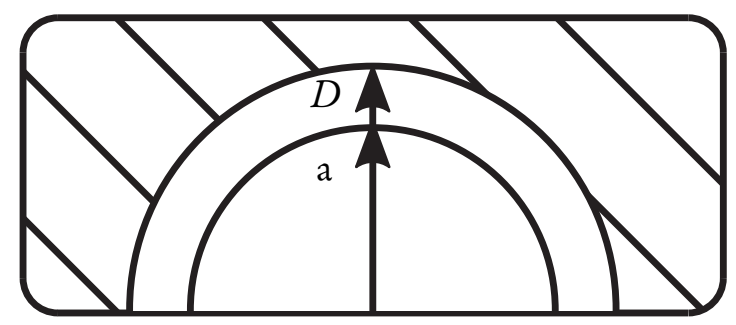

Figure 1: Surface crack with indicated crack length $a$ and damaged zone $D$. 

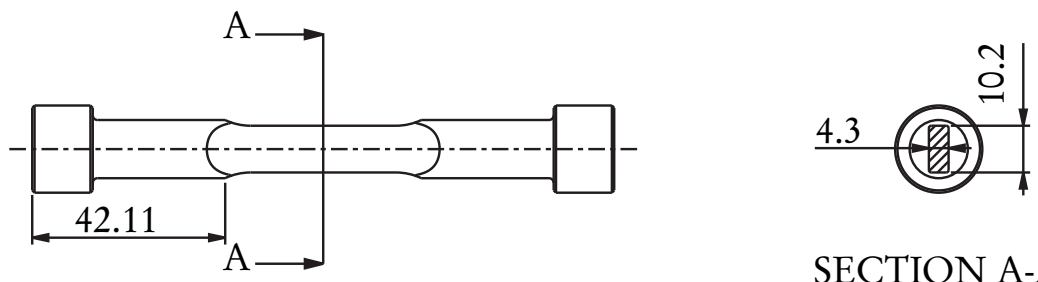

SECTION A-A
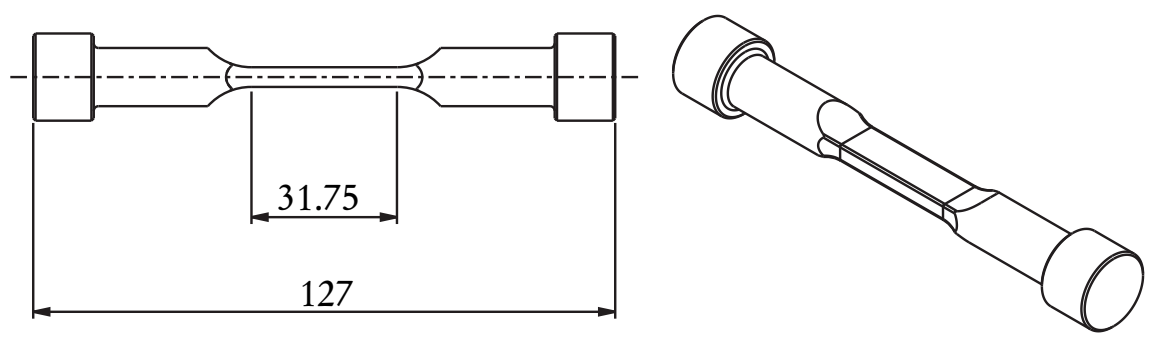

Figure 2: Kb-specimen with its rectangular cross section, dimensions in $\mathrm{mm}$.

$550^{\circ} \mathrm{C}$. From post-mortem beach marks on fracture surfaces, a study of how the crack length and damaged zone have developed for different load cycles are performed. Further investigation of fracture surfaces using scanning electron microscope (SEM) has also been conducted in order to complement the study of evaluation methods and PD measurements. With these observations, a successful description of the observed differences between the evaluation methods is reached.

\section{Experiments}

\subsection{Experimental procedure}

Fatigue crack growth tests were performed, by load control, at $550^{\circ} \mathrm{C}$ on wrought Inconel 718 with an approximate grain size of $10 \mu \mathrm{m}$ using Kb-type (surface crack) specimens with rectangular cross sections of $4.3 \times 10.2 \mathrm{~mm}$, see Fig. 2. The initial notch was created by electro discharge machining (EDM), and subsequent pre cracking was done at room temperature using a $10 \mathrm{~Hz}$ sine wave with a max load of 650 $\mathrm{MPa}$ and $R_{\sigma}=0.05$. Crack growth was monitored by direct current potential drop (DCPD), while the subsequent stress intensity factor (SIF) evaluation [19] was done by assuming a semi-circular crack front.

\subsection{Evaluation methods}

In all tests the point of consideration was the deepest point of the crack geometry, for which the cracked area was evaluated through a calibration curve, derived from either (i) the post mortem fracture surface observations, or from (ii) a pre-made pure cyclic test by measuring induced beach marks on the fracture surface resulting from temperature changes. In the former case a linear curve is used for describing the relation between the PD value and the crack area $\left(i_{a}\right)$ or crack length $\left(i_{b}\right)$, where the two end points will be the end of the pre-crack and the start of the final fracture surface, respectively, see Fig. 3 for an overview of the explained methods.

More specifically, in method ( $\left.i_{a}\right)$ Eq. (1) is used for translating the PD values from the cracked area from the fracture surface to crack length, i.e. the fractured 

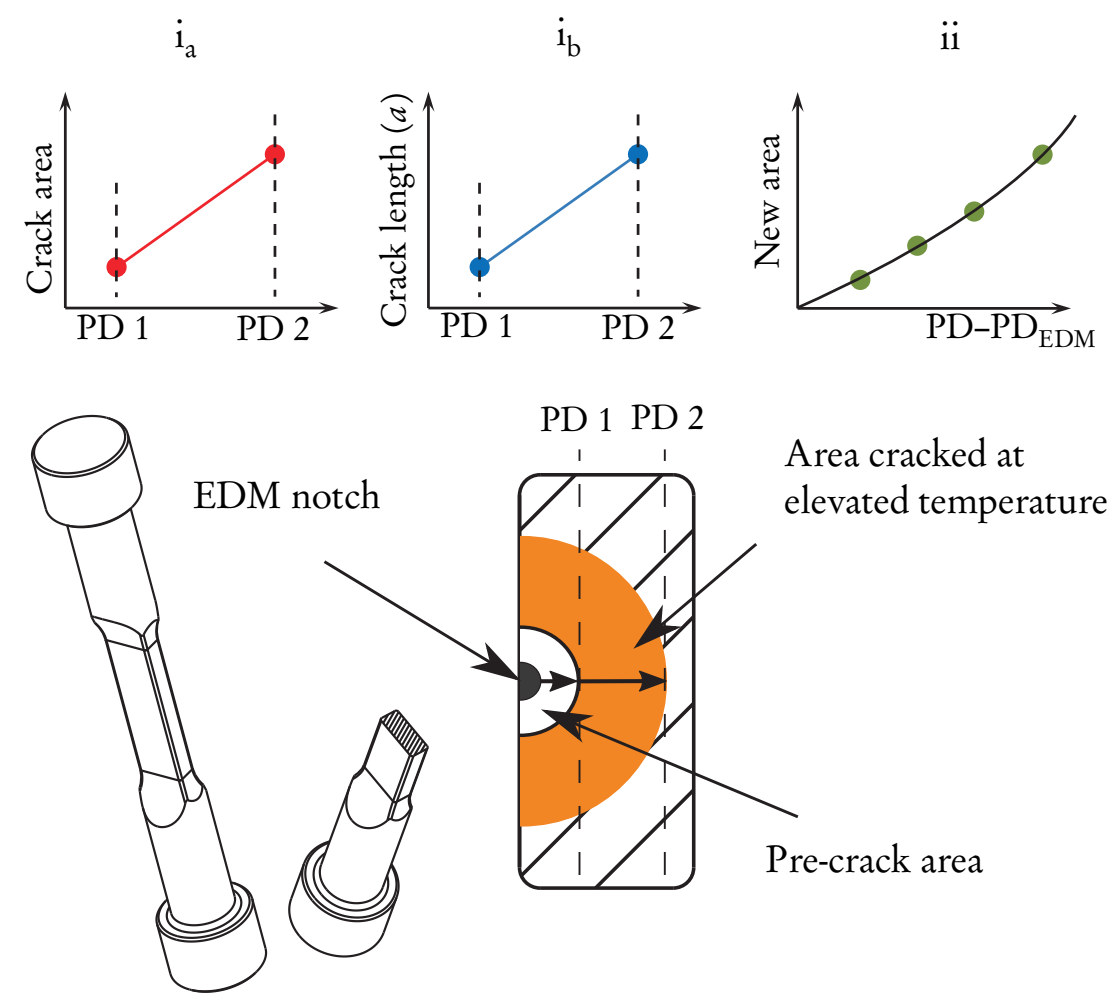

Figure 3: Overview of the three different evaluation techniques.

area is assumed to be proportional to the PD signal. The values in Eq. (1) is derived by examining the post-mortem fracture surface in each test, and then subsequently setting up the necessary linear line parameters, cf. Fig. 3 (far left plot marked with $\left.i_{a}\right)$.

$$
\begin{aligned}
& \text { Area }=k_{i_{a}} \times \mathrm{PD}+m_{i_{a}} \\
& a=\sqrt{\frac{2 \times \text { Area }}{\pi}}
\end{aligned}
$$

Evaluation method ( $i_{b}$ ) utilises Eq. (2) for directly transmitting equivalent crack length (derived from the surface area), assumed to be proportional to the PD signal on the post-mortem fracture surfaces. The parameters for the equation is gained by examining each post-mortem fracture surface together with the associated PD value,

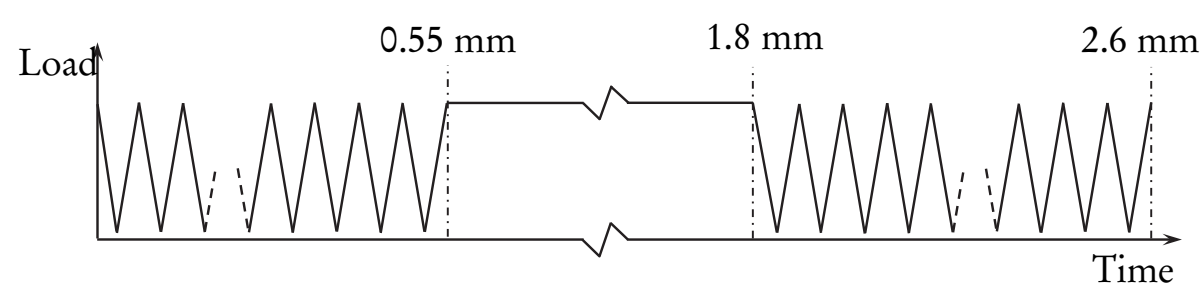

Figure 4: Test sequence for the mixed test, crack length markings indicating block mode change (by PD from method (ii)). 
Table 1: Summary of the different tests performed, crack lengths $[\mathrm{mm}](K[\mathrm{MPa} \sqrt{\mathrm{m}}])$ values based on PD evaluations (method (ii)).

\begin{tabular}{lllll}
\hline Test type & $a_{\text {start }}$ & $a_{\text {end block 1 }}$ & $a_{\text {end block 2 }}$ & $a_{\text {final }}$ \\
\hline Cyclic & $0.35(14.8)$ & - & - & $2.00(35.4)$ \\
Mixed & $0.24(11.8)$ & $0.53(17.6)$ & $1.80(33.3)$ & $2.59(41.0)$ \\
Sustained & $0.49(16.9)$ & - & - & $2.50(40.2)$ \\
\hline
\end{tabular}

and exactly as with method $\left(i_{a}\right)$ above, derive the linear line parameters, cf. Fig. 3 (middle plot marked with $i_{b}$ ).

$$
a=k_{i_{b}} \times \mathrm{PD}+m_{i_{b}}
$$

In the latter case, i.e. method (ii), a polynomial expression for the newly produced crack area may be set up between the different beach marks gained from the temperature changes in the pre-made cyclic test. In this method the newly produced crack area is defined to be from the EDM notch, i.e. the first PD value is gained from when mounting the test specimen, which is then subtracted from the measured PD signal. To derive the polynomial expression used for evaluating the crack length, the PD value (subtracted from the EDM notch), is plotted to its respective newly produced cracked area (from the induced beach marks), see Fig. 3 (far right plot marked ii). In this specific setup, see Eq. (3), a second degree polynomial expression is used to describe this process. Clearly, method (ii) incorporates the effect of areas with ligaments and islands, and also provides the means of measuring the damaged zone as the difference between the final crack length seen on a post-mortem fracture surface and the associated PD-based length value; a possibility not provided by method (i).

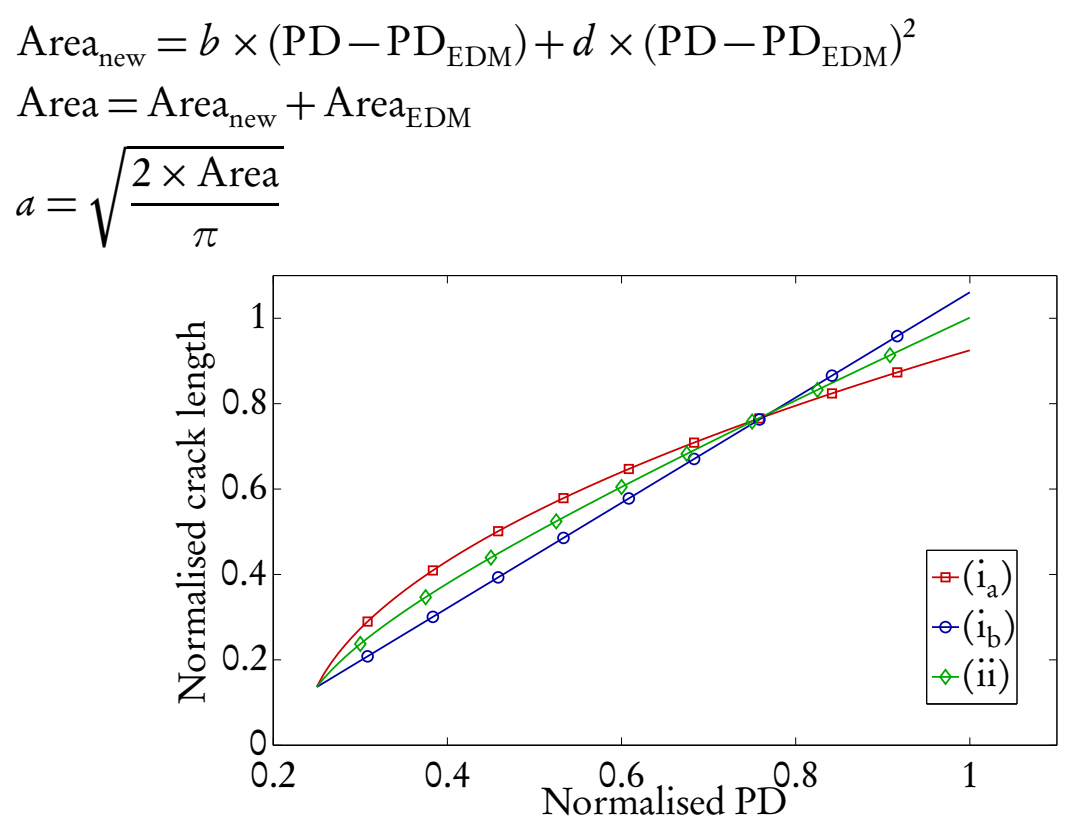

Figure 5: Different growth rates depending on the crack length evaluation method. 


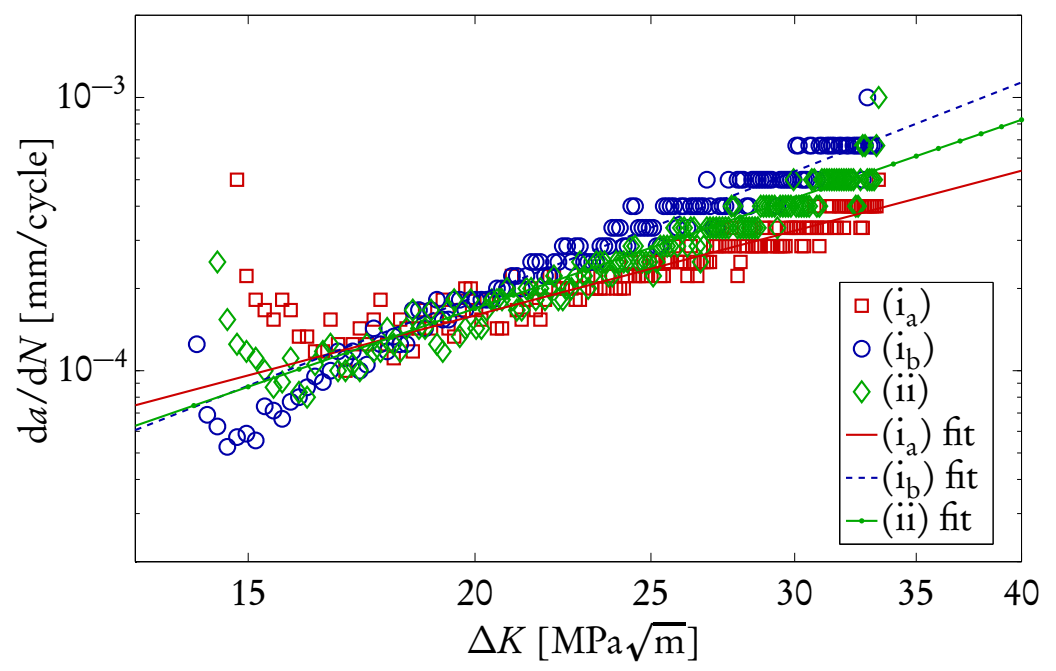

Figure 6: The cyclic test evaluated with the three different methods.

\subsection{Performed tests}

The tests used in this study are of three different types, all for $550^{\circ} \mathrm{C}$, namely

- Cyclic load test: $0.5 \mathrm{~Hz}, \sigma_{\max }=650 \mathrm{MPa}, R_{\sigma}=0.05$

- Test with a mix of sustained and cyclic loads: $0.5 \mathrm{~Hz}, \sigma_{\max }=650 \mathrm{MPa}, R_{\sigma}=0.05$

- Sustained load test: $\sigma_{\max }=650 \mathrm{MPa}$

where the mixed test of sustained and cyclic load, see Fig. 4, is used for calibrating a developed crack growth model $[17,20]$, where the test specimen is subjected to continuous cycling to a crack length of $0.55 \mathrm{~mm}$, after which it is subjected to a hold time loading to a crack length of $1.8 \mathrm{~mm}$, during which the crack growth rate $\mathrm{d} a / \mathrm{d} t$ attains a linear behaviour in a log-log plot vs $K_{\max }$, see Fig. 11 and [17]. Finally, the specimen is subjected to continuous cycling to a final crack length of about 2.6 $\mathrm{mm}$. All load reversals were conducted at $R_{\sigma}=0.05$ with a $0.5 \mathrm{~Hz}$ sine wave. The other two tests were performed from an initial crack length of $0.5 \mathrm{~mm}$ and $0.35 \mathrm{~mm}$, respectively, to a final crack length of $2.5 \mathrm{~mm}$ and $2.0 \mathrm{~mm}$, respectively (by PD from method (ii)) and a max load of $650 \mathrm{MPa}$. A complete summary of the different tests performed is found in Table 1.

\section{Results and discussion}

\subsection{Cyclic test}

The standard cyclic test was performed to see the influence of the different evaluation methods described in the above section. More specifically, different crack propagation rates will be gained. The first method $\left(i_{a}\right)$ where the fracture surface area is assumed to be proportional to the PD signal is based on how the cracked area is evolved, which is in contrast to method $\left(i_{b}\right)$ where the crack length is used for calibrating the crack growth rate. The difference between the two methods is clear, for $\left(i_{a}\right)$ the time to reach a larger area corresponding to the same crack length as in 


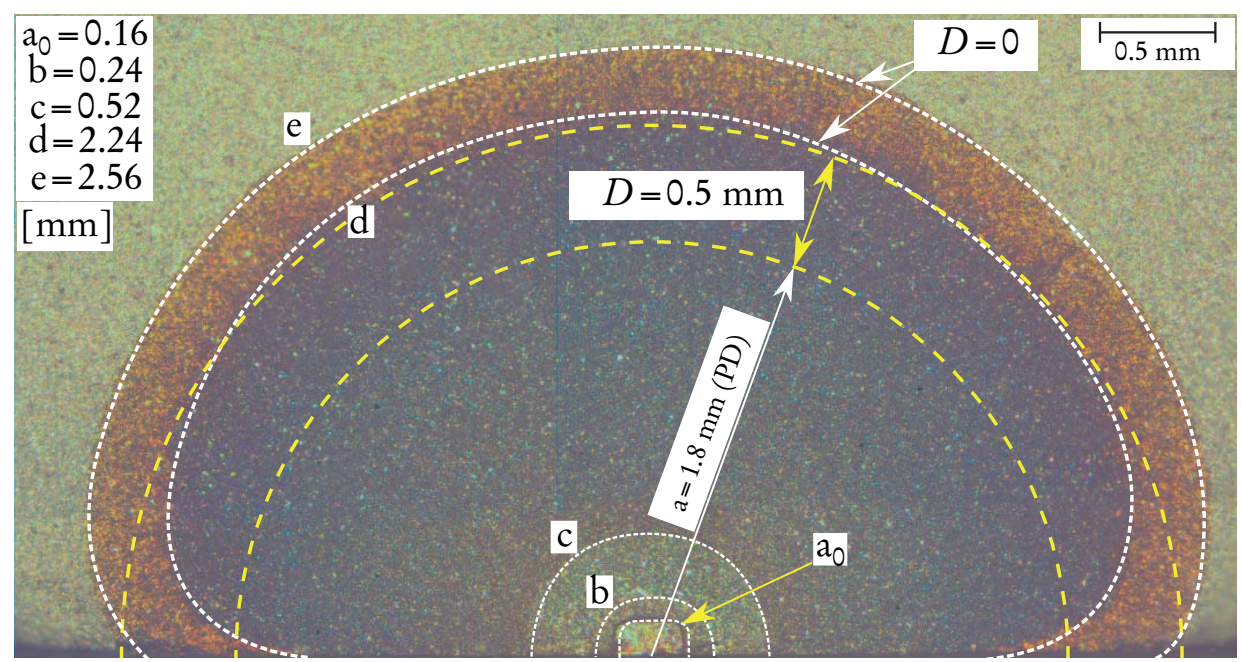

Figure 7: Fracture surface with markings for the mixed test and associated equivalent crack lengths (in white), where $\mathrm{a}=1.8 \mathrm{~mm}$ originates from evaluation method (ii) and the equivalent damaged zone marking (in yellow).

$\left(i_{b}\right)$ will have to be faster due to the semi-circular area expression. However, as the cracked area reaches a higher value the growth rate will progressively slow down for method $\left(i_{a}\right)$. A similar behaviour can be seen for method (ii) where the crack area is derived through a second degree polynomial expression. Here the rate will be slightly less than the linear area expression but still faster than method $\left(\mathrm{i}_{\mathrm{b}}\right)$ where the crack length is considered to be linear with respect to the PD value, see Eq. (1) vs. Eq. (2) vs. Eq. (3) and Fig. 5.

The above behaviour will of course be reflected on the crack propagation rate description by giving different Paris law parameters, which will in turn affect life to failure predictions. By considering this and observing Fig. 6 where the result for the cyclic test is presented, one can conclude that the difference is not negligible.

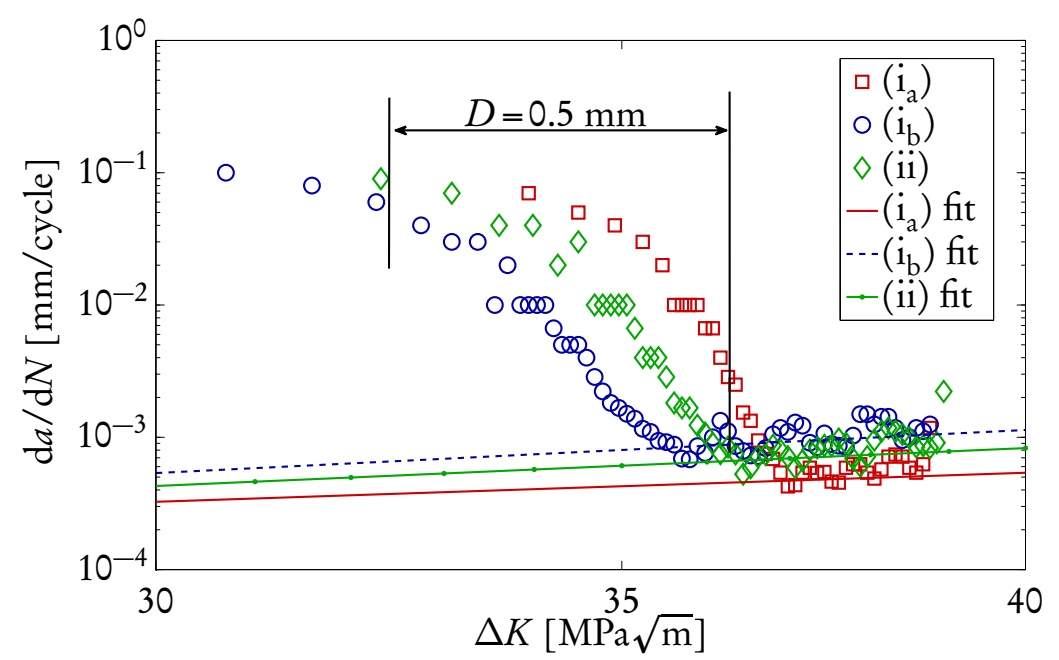

Figure 8: Crack propagation rate of the second cyclic block in the mixed test, with damaged zone measurement for evaluation method (ii). 
Table 2: Crack lengths for measurements on fracture surface and PD evaluations for method (ii).

\begin{tabular}{llllll}
\hline Area & $a_{\text {frac. surface }}[\mathrm{mm}]$ & $\mathrm{a}_{\mathrm{PD}}[\mathrm{mm}]$ & $\mathrm{a}_{\text {frac. surface }} / \mathrm{a}_{\mathrm{PD}}$ & $\mathrm{a}_{\mathrm{PD}}+D(0.5 \mathrm{~mm})$ & $\mathrm{a}_{\text {frac. surface }} /\left(\mathrm{a}_{\mathrm{PD}}+D\right)$ \\
\hline $\mathrm{a}_{0}$ & 0.16 & - & - & - & - \\
$\mathrm{b}$ & 0.24 & 0.24 & 1.00 & - & - \\
$\mathrm{c}$ & 0.52 & 0.53 & 0.98 & - & - \\
$\mathrm{d}$ & 2.24 & 1.80 & 1.25 & 2.3 & 0.97 \\
$\mathrm{e}$ & 2.56 & 2.59 & 0.99 & - & - \\
\hline
\end{tabular}

\subsection{Mixed test}

On the fracture surface in Fig. 7, one can see induced (white) markings, caused by the different loading modes the specimen have been subjected to, where one can identify (from the crack start at the bottom of the notch to the end of final crack): $\left(a_{0}\right)$ the initial notch, (b) the pre-crack (c) the first cyclic block, (d) a zone marking the end of the hold time block (including the damaged zone $D$ ), and finally (e) an area marking the situation where the crack has propagated through the damaged zone and into unaffected material (not affected by any material damage). Each marking is given an equivalent length, which is derived from area measurements, and converted to an effective distance using the assumed semi-circular crack shape, i.e. the same way the PD signal is evaluated. In addition, two markings gained from evaluation method (ii) are shown (both marked in yellow), 1) the end of the hold time block and 2) the equivalent damaged zone derived from evaluating Fig. 8.

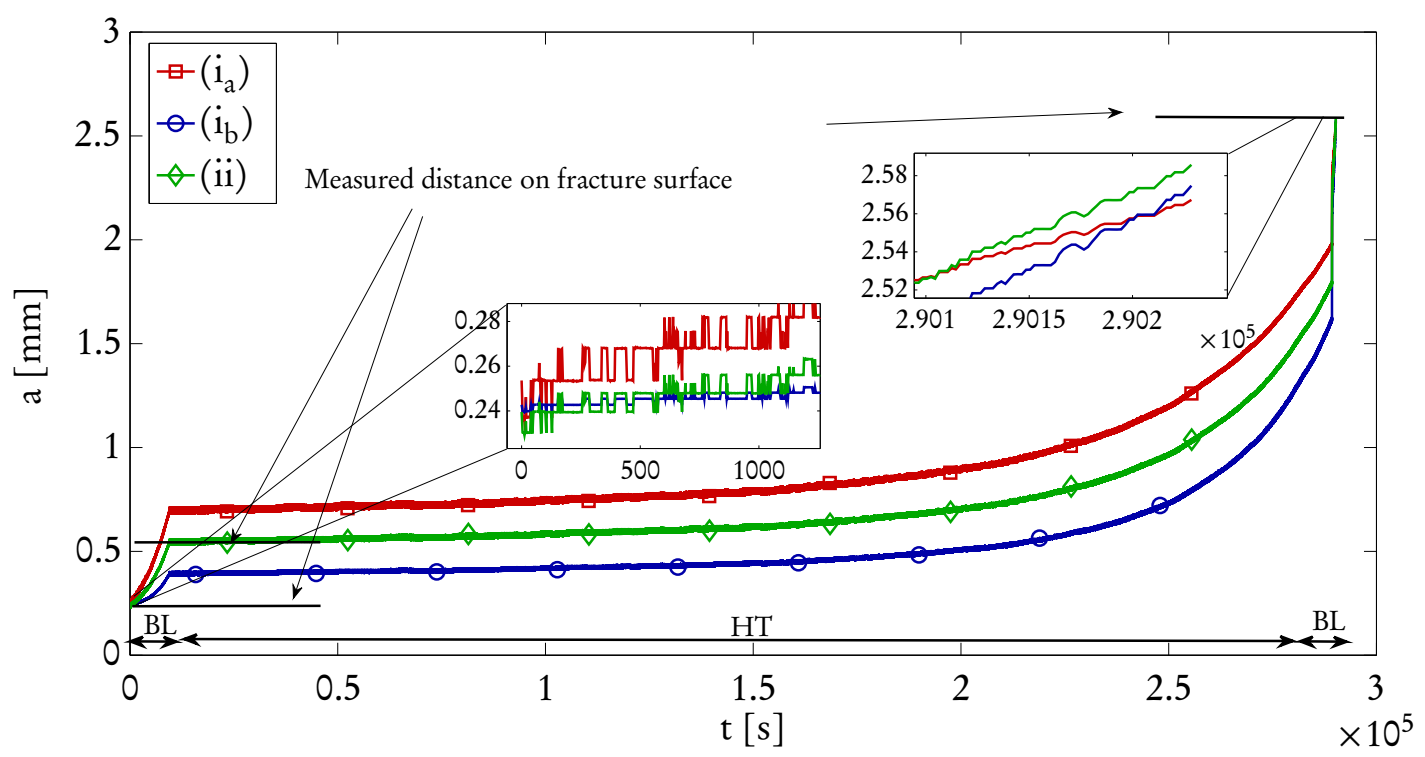

Figure 9: The mixed test evaluated with the different methods, note the clear difference where the measurements on the fracture surface are presented. Notation BL indicate cyclic load while HT indicate hold time load.

The region defined by (d) in Fig. 7 includes a damaged zone, consisting of ligaments and islands of unbroken material with reduced strength to crack propagation. 


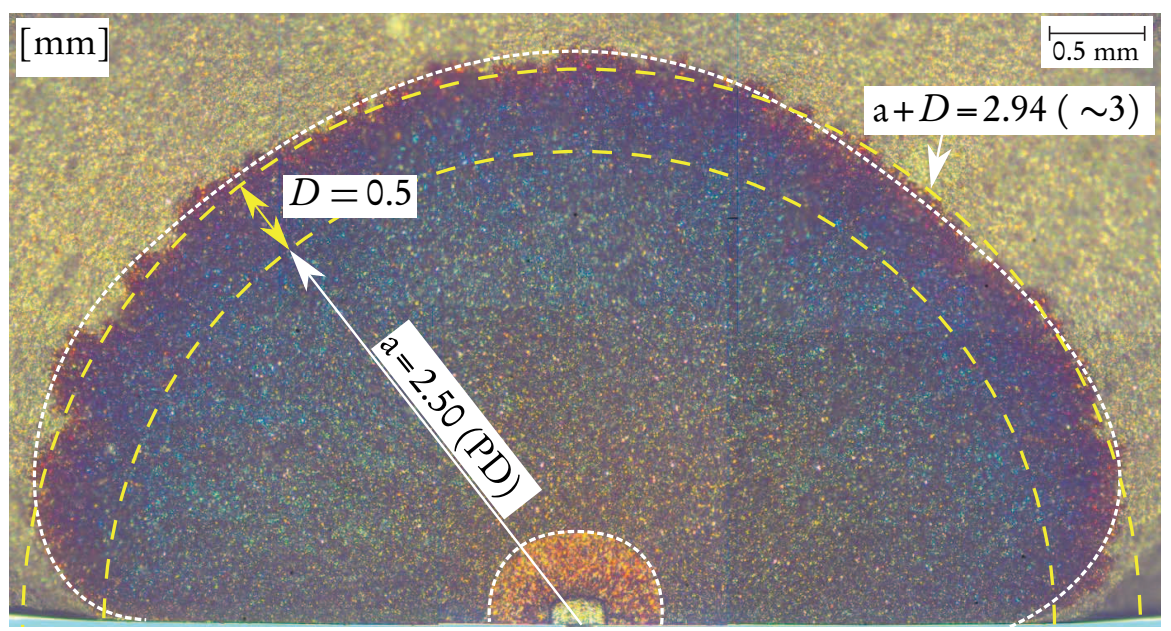

Figure 10: Fracture surface with markings for the sustained load test and associated equivalent crack lengths, evaluation method (ii) is used to derive the damaged zone length $D$.

For details see Table 2. To further manifest the existence and size of the damaged zone, also the crack growth rate $\mathrm{d} a / \mathrm{d} N$ over $\Delta K$ may be studied, see Fig. 8 . Here one can clearly see how the crack propagation rate is decreasing as the damaged zone is consumed, i.e. as the islands and ligaments of unbroken material are broken apart until only undamaged material remains. Consequently, when the damaged zone is completely consumed, the crack growth rate is back on the stabilised baseline level. The result for evaluation methods $\left(i_{a}\right)$ and $\left(i_{b}\right)$ can also be found in Fig. 8. Again, the difference in predicted behaviour is non-negligible.

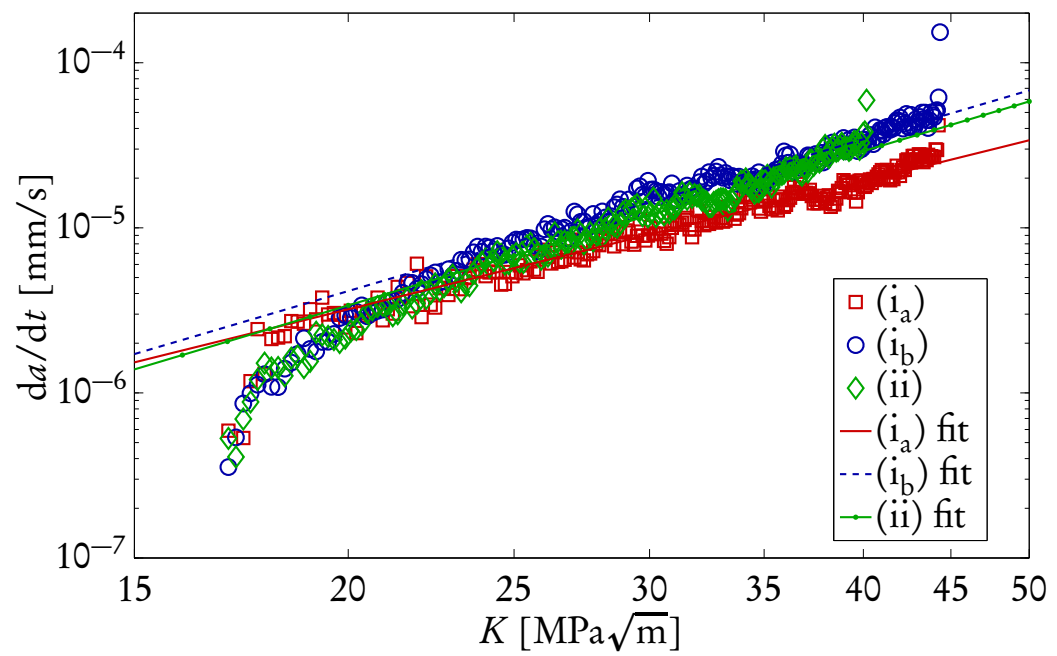

Figure 11: Different growth rates depending on the crack length evaluation method, note the difference in $K$ depending on the evaluation method.

When looking at the crack propagation for the complete mixed test, see Fig. 9, it is clear that method $\left(i_{a}\right)$ will overpredict the crack growth rate, in contrast to method $\left(i_{b}\right)$ which will underpredict it. The only method which accurately predicts the correct behaviour is method (ii) where the pre-defined calibration curve will display the 
correct crack length. The small discrepancy in start and end values for the different evaluation methods is most likely due to the fact that the measurements on the fracture surface is not as accurate as the PD measurements are to describe the fracture surface and also due to numerical rounding off when constructing the different calibration curves. The observations from this clearly shows how one must evaluate the PD signals in order for a correct crack growth behaviour when considering tests with mixed sustained and cyclic loading.

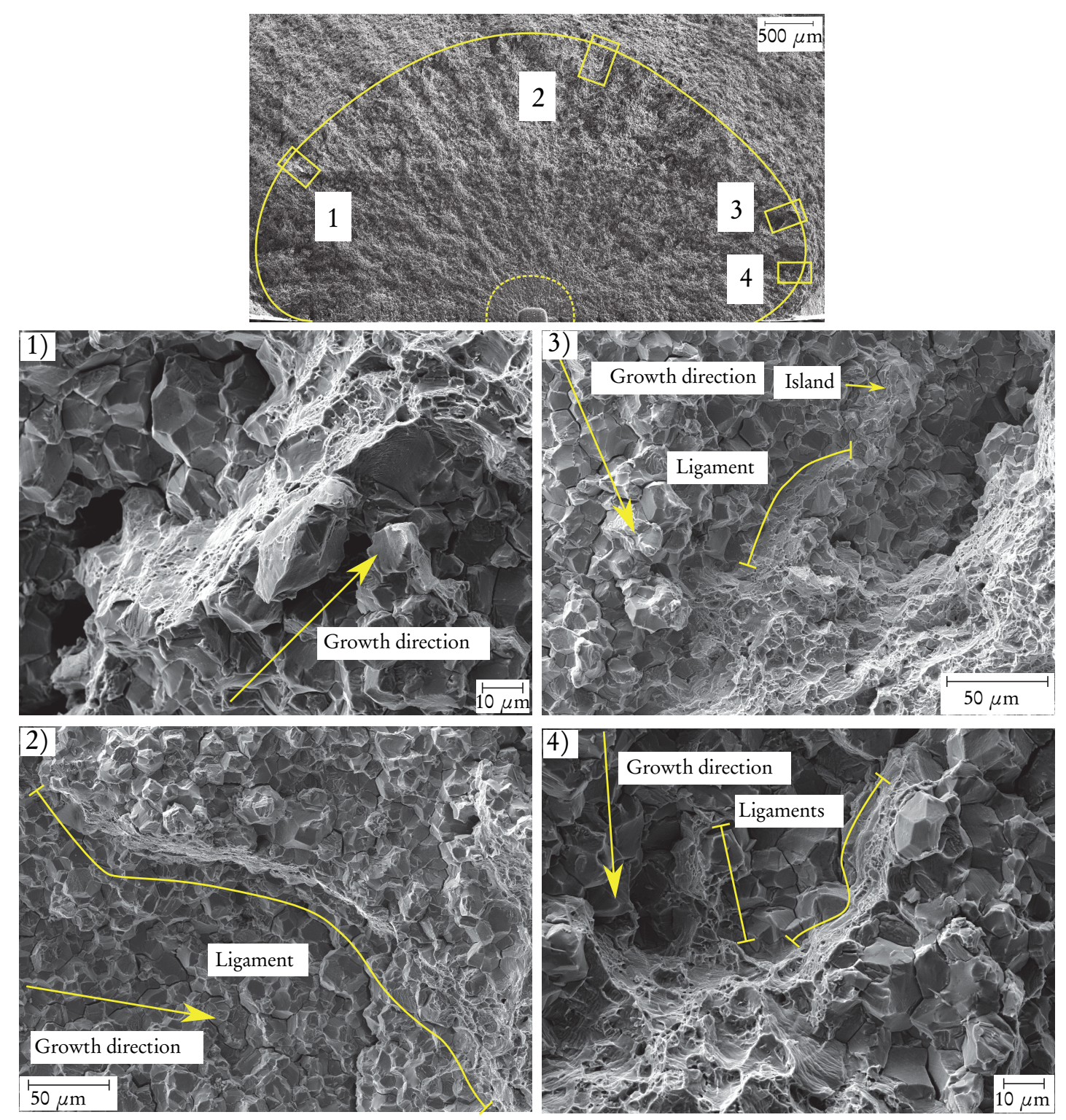

Figure 12: SEM images of the sustained load test fracture surface, zoom in on areas with ductile fracture.

\subsection{Sustained load test}

The fracture surface of this test is shown in Fig. 10. For the test the measured final crack length on the fracture surface was $2.94 \mathrm{~mm}$ while the calculated, $a+D$ 
(with $a=2.5 \mathrm{~mm}$ taken from $\mathrm{PD}$, and $D=0.5 \mathrm{~mm}$ from Fig. 8 using method (ii)), gave $3 \mathrm{~mm}$; the test was therefore considered to give the same amount of damaged zone as the mixed test as previously discussed in Section 3.2.

By studying the fracture surface and the influence of the different evaluation methods in Fig. 11, one can see a similar behaviour as for the cyclic load test, higher crack growth rate for method $\left(i_{a}\right)$ in which the crack area is proportional to the PD signal. A similar increase can be seen for method $\left(i_{b}\right)$ as the crack length increases, which can also be seen in Fig. 5. The most striking difference in this test compared to the others is that now the damaged zone really plays a central role when studying the final crack length and the resulting $K$ value.
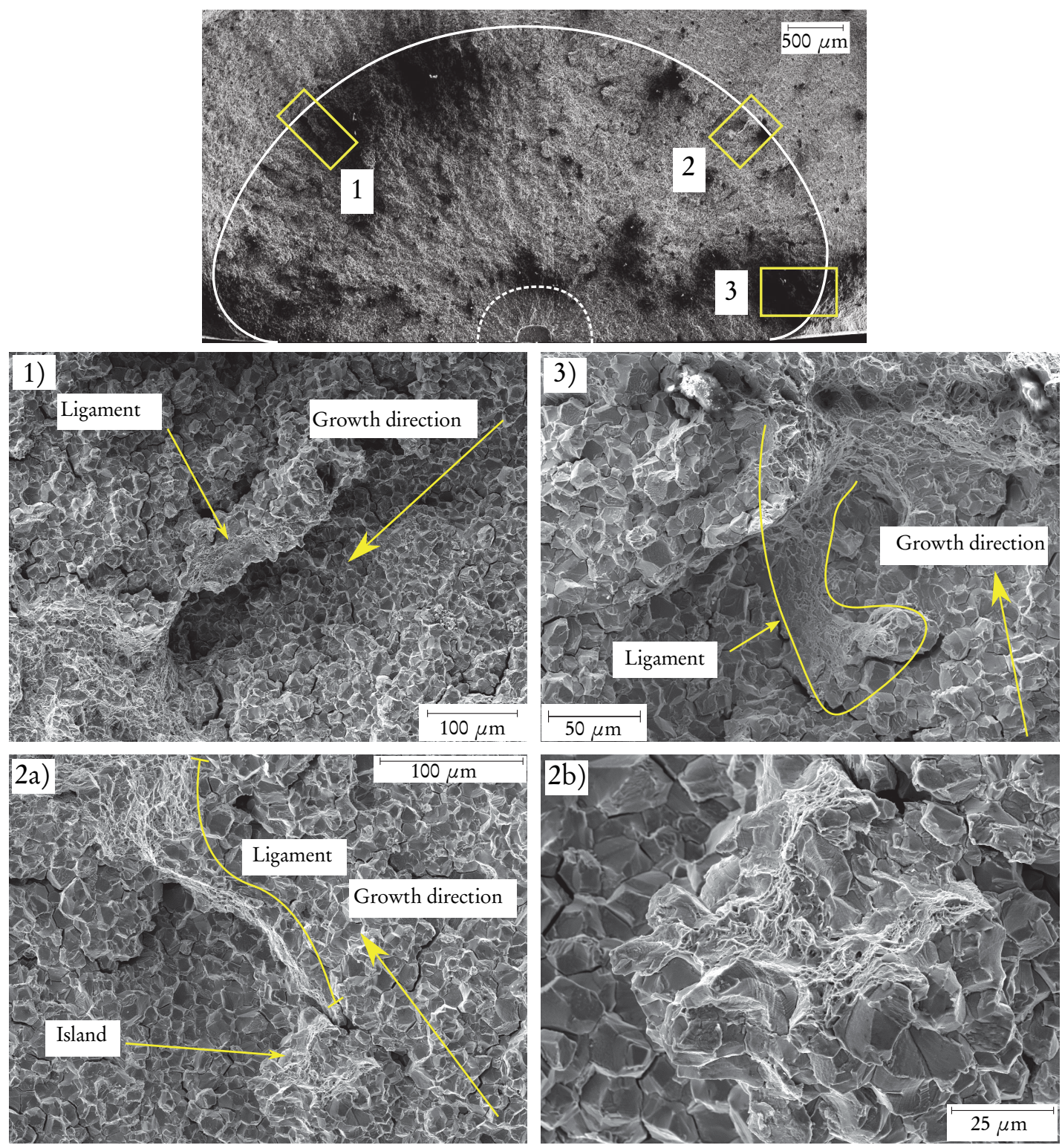

Figure 13: SEM images of the identical sustained load test fracture surface, zoom in on areas with ductile fracture. 


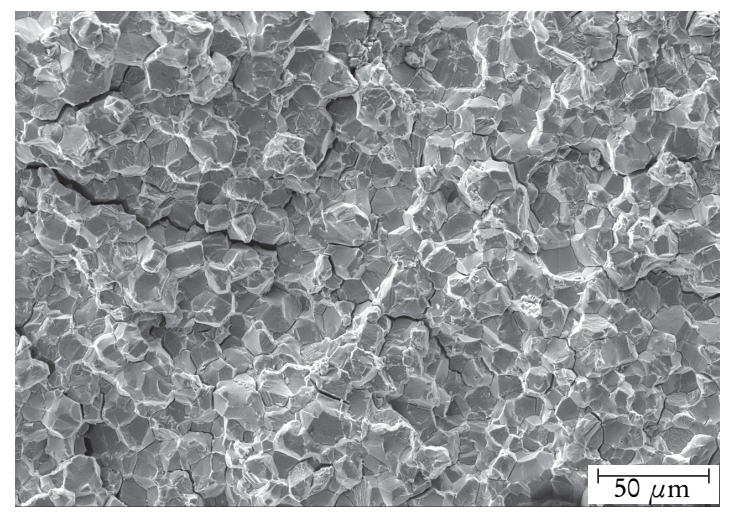

(a)

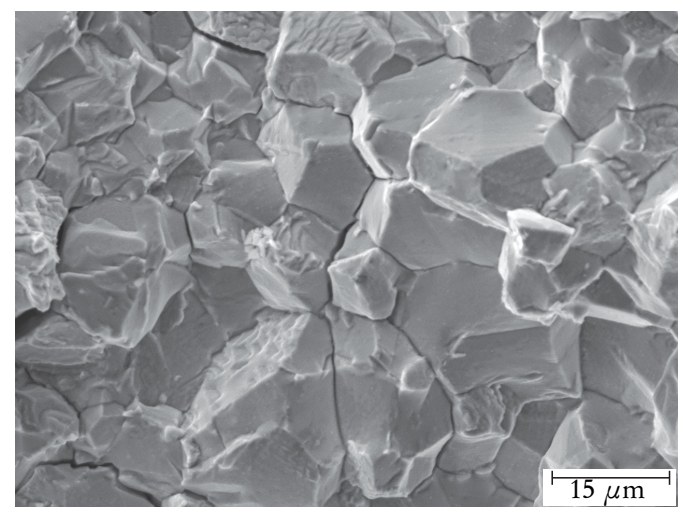

(b)

Figure 14: Examples of intergranular fracture remote from the final crack tip.

\subsubsection{Investigation of the fracture surface}

An investigation of the above fracture surface (Fig. 10) was conducted to see how method (ii) relates to the PD signal by using scanning electron microscopy (SEM) with a Hitachi SU-70. This particular fracture surface used was considered to be the most interesting one due to the fact that a damaged zone will be left on the fracture surface as this test has only been exposed to a sustained load. Images of the fracture surface is seen in Fig. 12 with a number of closer investigations to see how the PD signal might interfere with the different ligaments of unbroken material.

The most notable thing is the high irregularity seen in the intergranular cracking on the part where the dwell time crack growth has occurred, caused by weakening and subsequent cracking as discussed in Section 1. Four distinct regions of unbroken ligaments and islands of unbroken material are identified on the fracture surface. These held the fracture surfaces together when the embrittling of the grain boundaries had taken place and have later been cracked in ductile mode when the test specimen was eventually broken apart.

In addition to the fracture surface study of the sustained load test, one additional identical test was set up to confirm the build-up of the damaged zone. This test was in all ways identical to the previous sustained load test, but unfortunately suffered from an error in the PD signal processing system. As a result, the monitored crack length from this test was deemed unreliable for a more quantitative study. Nevertheless, the fracture surface itself is as valid as the others for structural examinations. Consequently, this test was then prepared and examined in the same way as the previous test. In Fig. 13 three distinct areas of ductile fracture at the edge of final fracture are identified. Note that the black areas on the fracture surface were concluded to be carbon pollution.

The only locations with a ductile fracture mode on the damaged zone were, as seen in Fig. 12 and Fig. 13, near the edge of the final fracture surface (i.e. intergranular fracture on the rest of the fracture surface, cf. Fig. 14 taken remote from the final crack tip) as these grains have not been exposed to the embrittling mechanism for as long time as the ones further behind. 


\section{Summary and conclusions}

Evaluation of fatigue crack propagation under dwell time conditions has been conducted for the temperature $550^{\circ} \mathrm{C}$. Three test types were used, 1) a cyclic test, 2) a specially designed test denoted mixed test for model calibration, see [17] and 3) a sustained load test. From the observed crack propagation behaviour and postmortem fracture surface investigations, it can be concluded that the damaged zone is an inherent part of the fracture surface, and not covered by the PD method. With these observations it becomes apparent that the damaged zone has to be incorporated into fracture surface measurements (e.g. when breaking test specimens for setting up post-mortem PD reference curves) and in the development of history dependent crack propagation models. Some additional conclusions are:

- Depending on the evaluation method different crack propagation rates are obtained, which may have a substantial effect on the life modelling of critical components in e.g. gas turbines.

- Correct crack length observations on a fracture surface with tests including dwell times is gained with a pre-defined calibration curve using a damaged zone concept where unbroken ligaments are electrically conductive.

- Evaluation method (ii) provides for the most physically sound explanation when evaluating crack propagation rates for test involving sustained load.

\section{Acknowledgements}

The authors would like to thank Lic. Eng. Mattias Calmunger and Dr. Robert Eriksson, Linköping University, for the SEM support, Mr. Patrik Härnman and Mr. Bo Skoog, Linköping University, for the laboratory work, and the project teams at Linköping University, Siemens Industrial Turbomachinery AB and GKN Aerospace Engine Systems for valuable discussions. This research has been funded by the Swedish Energy Agency, Siemens Industrial Turbomachinery AB, GKN Aerospace Engine Systems, and the Royal Institute of Technology through the Swedish research programme TURBO POWER, the support of which is gratefully acknowledged.

[1] J.P. Pédron, A. Pineau. The effect of microstructure and environment on the crack growth behaviour of Inconel 718 alloy at $650{ }^{\circ} \mathrm{C}$ under fatigue, creep and combined loading. Material Science and Engineering, 56(2):143-56, 1982.

[2] J.M. Larsen, T. Nicholas. Load sequence crack growth transients in a superalloy at elevated temperature. Fracture Mechanics: Fourteenth Symposium - Volume II: Testing and Applications, ASTM STP 791, pages II-536-II-552, 1983.

[3] T. Nicholas, T. Weerasooriya. Hold-time effects in elevated temperature fatigue crack propagation. Fracture Mechanics: Seventeenth Volume, ASTM STP 905, pages 155-168, 1986.

[4] T. Weerasooriya. Effect of frequency on fatigue crack growth rate of Inconel 718 at high temperature. Technical report, Air Force Wright Aeronautical Laboratories Report, AFWAL-TR87-4038, Wright-Patterson Air Force Base, OH, 1987.

[5] H. Ghonem, D. Zheng. Depth of intergranular oxygen diffusion during environment-dependent fatigue crack growth in alloy 718. Materials Science and Engineering: A, A150(2):151-160, 1992.

[6] E. Andrieu, R. Molins, H. Ghonem, A. Pineau. Intergranular crack tip oxidation mechanism in a nickel-based superalloy. Materials Science and Engineering: A, 154(1):21-28, 1992. 
[7] H. Ghonem, T. Nicholas, A. Pineau. Elevated temperature fatigue crack growth in alloy 718-part II: Effects of environmental and material variables. Fatigue $\mathcal{E}$ Fracture of Engineering Materials $\mathcal{E}$ Structures, 16(6):577-590, 1993.

[8] J.A. Pfaendtner, C.J. McMahon Jr. Oxygen-induced intergranular cracking of a Ni-base alloy at elevated temperatures - an example of dynamic embrittlement. Acta Materialia, 49(16):33693377, 2001.

[9] F.V. Antunes, J. M. Ferreira, C. M. Branco, J. Byrne. Influence of stress state on high temperature fatigue crack growth in Inconel 718. Fatigue \& Fracture of Engineering Materials \& Structures, 24(2):127-135, 2001.

[10] D. Gustafsson, J.J. Moverare, S. Johansson, M. Hörnqvist, K. Simonsson, S. Sjöström, B. Sharifimajda. Fatigue crack growth behaviour of Inconel 718 with high temperature hold times. Procedia Engineering, 2(1):1095-1104, 2010. Fatigue 2010.

[11] D. Bika, J.A. Pfaendtner, M. Menyhard, C.J. McMahon Jr. Sulfur-induced dynamic embrittlement in a low-alloy steel. Acta Metallurgica et Materialia, 43(5):1895-1908, 1995.

[12] X.B. Liu, L.Z. Ma, K.M. Chang, E. Barbero. Fatigue crack propagation of Ni-based superalloys. Acta Metallurgica Sinica, 18(1):55-64, 2005.

[13] U. Krupp. Dynamic embrittlement - time-dependent quasi-brittle intergranular fracture at high temperatures. International Materials Reviews, 50(2):83-97, 2005.

[14] D.A. Woodford. Gas phase embrittlement and time dependent cracking of nickel based superalloys. Energy Materials: Materials Science and Engineering for Energy Systems, 1(1):59-79, 2006.

[15] U. Krupp, W.M. Kane, X. Liu, O. Dueber, C. Laird, C.J. McMahon Jr. The effect of grainboundary-engineering-type processing on oxygen-induced cracking of IN718. Materials Science and Engineering: A, 349(1-2):213-217, 2003.

[16] L. Viskari, M. Hörnqvist, K.L. Moore, Y. Cao, K. Stiller. Intergranular crack tip oxidation in a ni-base superalloy. Acta Materialia, 61(10):3630-3639, 2013.

[17] E. Lundström, K. Simonsson, D. Gustafsson, T. Månsson. A load history dependent model for fatigue crack propagation in Inconel 718 under hold time conditions. Engineering Fracture Mechanics, 118:17-30, 2014.

[18] C.J. McMahon Jr. Comments on "identification of SAGBO-induced damage zone ahead of crack tip to characterize sustained loading crack growth in alloy 783". Scripta Materialia, 54(2):305307, 2006.

[19] J.C. Newman Jr., I.S. Raju. Stress-intensity factor equations for cracks in three-dimensional finite bodies subjected to tension and bending loads. Technical report, NASA Technical Memorandum 85793, 1984.

[20] E. Lundström, K. Simonsson, T. Månsson, D. Gustafsson. Modelling of fatigue crack growth in Inconel 718 under hold time conditions - application to a flight spectrum. Advanced Materials Research, 891-892:759-764, 2014. 